\title{
Percent Predicted Inspiratory Capacity
}

National Cancer Institute

\section{Source}

National Cancer Institute. Percent Predicted Inspiratory Capacity. NCI Thesaurus. Code C112382.

The maximum volume of air a subject can inhale into the lungs after a tidal exhalation (IRV plus TV) as a proportion of the predicted normal value. (CDISC) 